\title{
INFRARED THERMOGRAPHY FOR DETECTING DEFECTS IN CONCRETE STRUCTURES
}

\author{
Gene F. SIRCA Jr., Hojjat ADELI* \\ Department of Civil, Environmental, and Geodetic Engineering, The Ohio State University, \\ 470 Hitchcock Hall, 2070 Neil Avenue, Columbus, Ohio, 43210 U.S.A.
}

Received 18 September 2018; accepted 04 October 2018

\begin{abstract}
The traditional methods for inspecting large concrete structures such as dams and cooling towers require erecting large amounts of scaffolding to access the surface of the concrete structure in order to sound the concrete with an impact device or hammer to expose the damaged or defective areas. Another method for accessing the surface of a large concrete structure is to employ climbing inspections which poses a considerable safety risk. These traditional methods are used to determine defect or damage within a few inches of the surface. In addition to the logistic difficulty of these methods a hammer can cause damage if care is not taken. Further, it can cover only a small area. Infrared Thermography (IRT), also referred to as thermal imaging, utilizes the infrared spectrum to show differences in heat dissipating from a structure using a thermal imaging camera. This paper presents a review of the IRT research for detecting defects in concrete structures. Health monitoring and damage detection of large structures such as bridges and high-rise buildings has been a very active area of research in recent years. The two main approaches explored by researchers are vibration-based health monitoring and camera-based vision technology. IRT remains to be another promising technology for economical health monitoring of structures.
\end{abstract}

Keywords: concrete structures, defect detection, damage detection, Infrared Thermography, health monitoring of structures.

\section{Research significance}

This paper presents a state-of-the-art review of the Infrared Thermography (IRT) research for detecting defects in concrete structures. IRT remains a promising technology for economical health monitoring of structures. The article encourages researchers to apply the IRT technology for health monitoring of large concrete structures. The success of IRT to detect defects or damage in large concrete structures would be a major breakthrough in NDE inspections of large structures such as dams and cooling towers as traditional methods are very costly and time consuming.

\section{Introduction}

Infrared Thermography (IRT), also referred to as thermal imaging, utilizes the infrared spectrum to show differences in heat dissipating from a structure using a thermal imaging camera. In simpler and broader terms, when a subject is heated by external sources such as the sun, ambient temperatures, friction, or other thermal sources it emits radiation in the long-infrared range of the electromagnetic spectrum which is detected by a thermographic camera. Figure 1 shows a typical arrangement of heat source and IRT camera to record thermal images. Note that the typical heat source for large structures is direct sunlight (often referred to as "flash thermography"). However, some research has shown that adequate ambient temperature change is often sufficient to detect defects (Guimaraes 2014).

Some of the common commercial uses for IRT include inspecting mechanical and electrical components such as bearings, gearboxes, electrical bus bars, and for detecting heat loss in buildings. To illustrate, Figures 2 and 3 show IRT images of a pillow block bearing and gearbox, respectively, those were taken by the first author as part of a mechanical inspection. The spectrum of color in such photos indicates the temperature at the surface ranging from white for the hottest to black for the coolest with other colors, yellow, orange, red, purple, and blue falling

${ }^{\star}$ Corresponding author. E-mail: adeli.1@osu.edu 

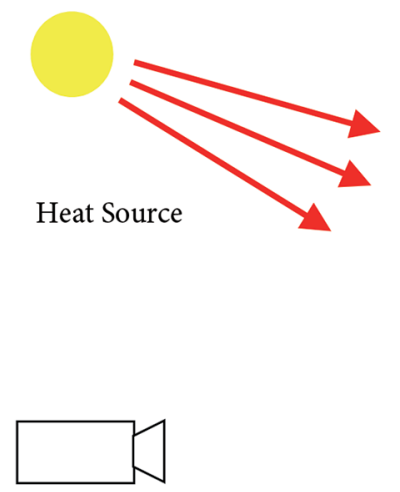

IRT Camera

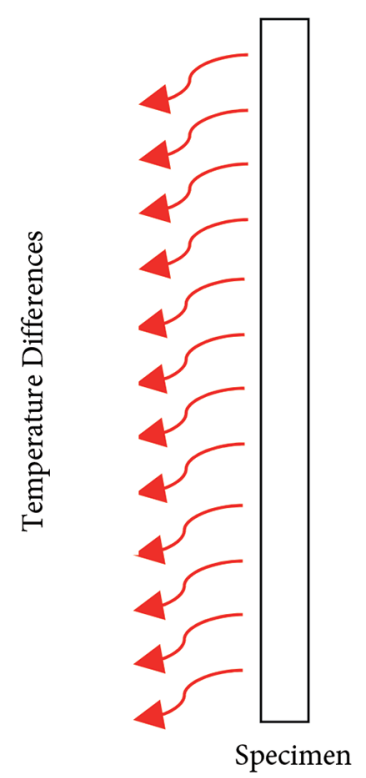

Figure 1. Typical arrangement of equipment for flash thermography

in between. The technique is somewhat new to civil engineering as a nondestructive evaluation (NDE) method for detecting damage or defects in concrete structures by providing a visual map of the surface of the structure that exhibits differences in heat dissipation to show areas where defects may exist. For concrete structures, the surface of the structure cools or heats from changes in direct sunlight or ambient temperature thus potentially highlighting defective areas of the concrete structure that heats or cools
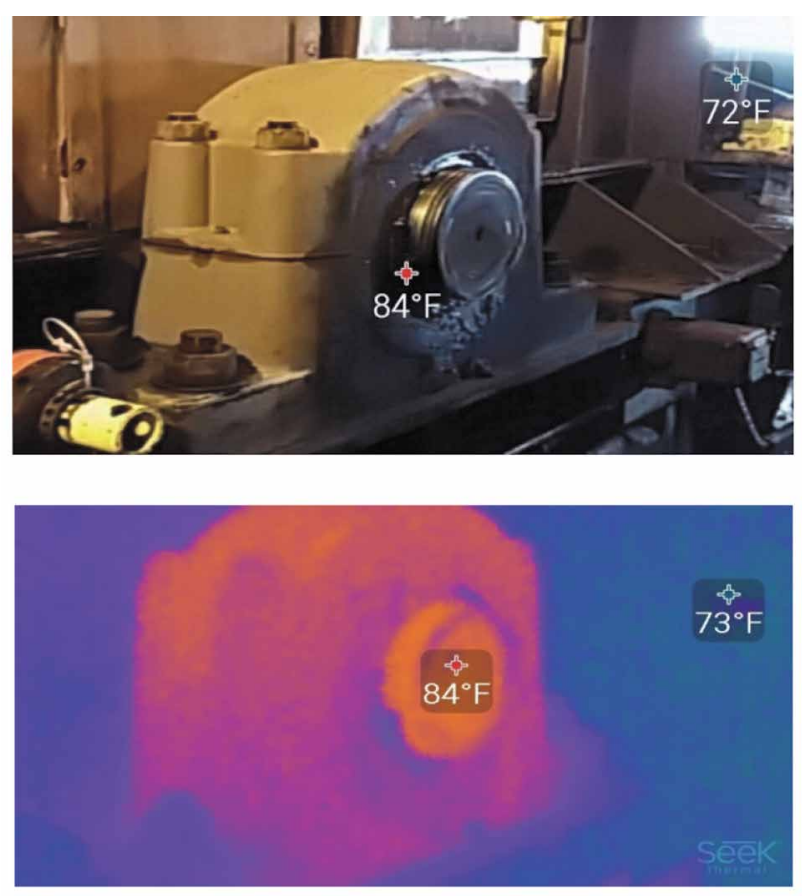

Figure 2. Thermal image of a pillow block bearing at different rates than non-flawed concrete. IRT can potentially detect defects in concrete up to a depth of 5 to 6 inches depending on the equipment used for recording the thermal image and the amount of thermal exposure (Guimaraes 2014). Renshaw et al. (2014) were able to detect a small crack on the order of $1 / 16$ inch wide, which was not documented using visual inspection methods, using IRT on a large dam structure. Furthermore, the defects detected using IRT generally aligned with known visible defects and the IRT method appears to have a very low probability of false identification.

The traditional methods for inspecting large concrete structures such as dams and cooling towers require erecting large amounts of scaffolding to access the surface of the concrete structure in order to sound the concrete with an impact device or hammer to expose the damaged or defective areas. Another method for accessing the surface of a large concrete structure is to employ climbing inspections which poses a considerable safety risk. These traditional methods are used to determine defect or damage within a few inches of the surface. In addition to the logistic difficulty of these methods a hammer can cause damage if care is not taken. Further, it can cover only a small area. Infrared Thermography (IRT), also referred to as thermal imaging, utilizes the infrared spectrum to show differences in heat dissipating from a structure using a thermal imaging camera. This paper presents a review of the IRT research for detecting defects in concrete structures. The success of IRT to detect defects or damage in large civil engineering structures would be a major breakthrough in NDE inspections of large structures such as dams and cooling towers as traditional methods are very costly and time consuming.
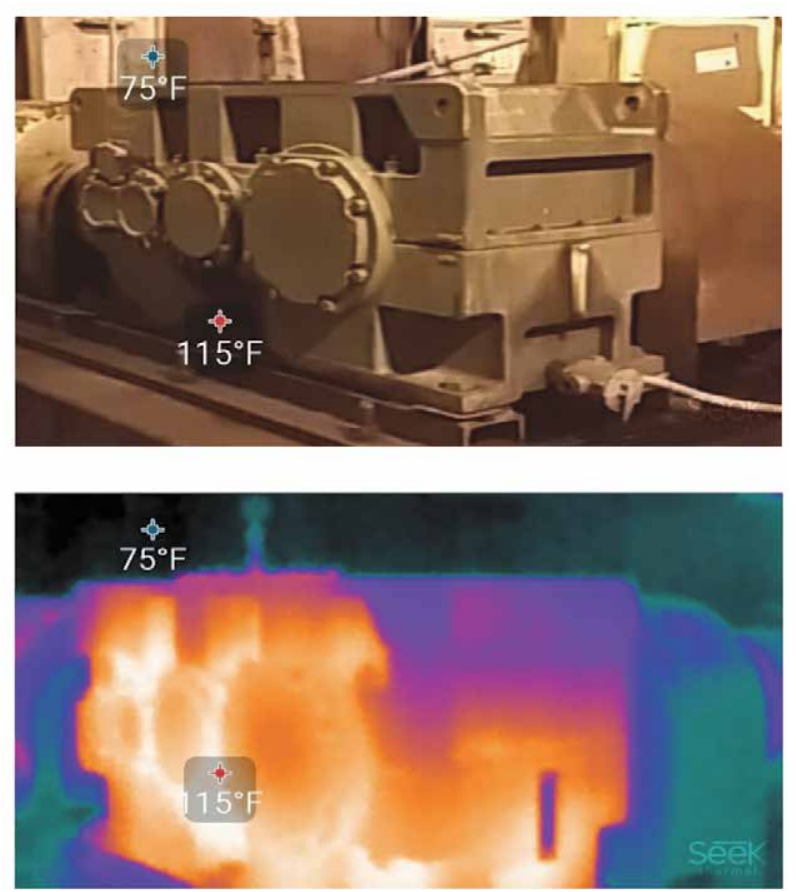

Figure 3. Thermal image of a gearbox 
The ability for a thermal imaging camera to detect damage or defects in concrete depends on how and when the images are recorded. For large civil structures such as dams and power plant cooling towers, the images should be taken at night while the structure is cooling from direct sunlight or ambient temperatures. Alternatively, the images may be taken in the morning during sunrise while the structure is heating after cooling overnight. For ambient temperature IRT, the temperature change must be large enough to record thermal images with discernible thermal gradients in order to detect damage or defects in the concrete. Therefore, it is necessary to consider the weather and the time of year when daily high and low temperatures are greatest to achieve the best results. One method to help overcome possible shortcomings from inadequate temperature change is to record time-lapse images of the structure. Post processing of the images helps to sharpen the image in order to detect defects in the concrete especially when ambient temperature differences are low or when there are large variations in temperatures. Other post processing techniques involve evaluating time lapse images for relative changes in temperature from image to image as the structure is heating or cooling.

Examples of large civil engineering concrete structures for IRT applications include hydroelectric dams (Figure 4), electric power plant cooling towers (Figure 5), and bridge decks (Figure 6). Figure 4 shows the American Electric Power's Claytor Hydroelectric facility located in Western Virginia which is an unreinforced concrete structure with a typical cross section shown in Figure 7.

The dam was a test subject for implementing several NDE techniques, one of which was IRT (Guimaraes 2014). Other NDE techniques that were considered include ground-penetrating radar and air-coupled impact-echo testing which were mounted on a remote controlled robot that crawls on the surface of the dam. The robot "crawler" is shown in Figure 8. Another type of dam structure is the double-curved Smith Mountain dam depicted in Figure 9. Figure 10 shows a thermal image taken of a cooling tower at Amos power plant in central West Virginia. The visual

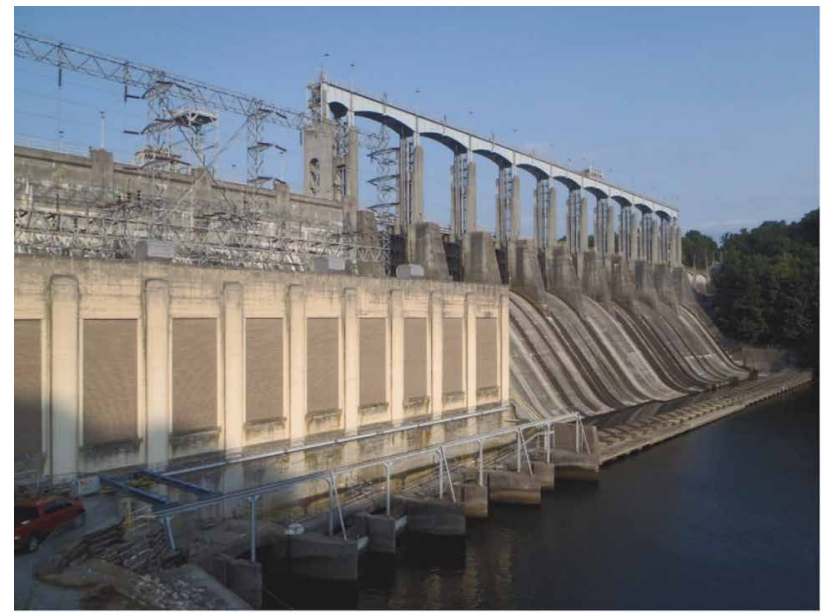

Figure 4. Claytor Hydroelectric facility and dam

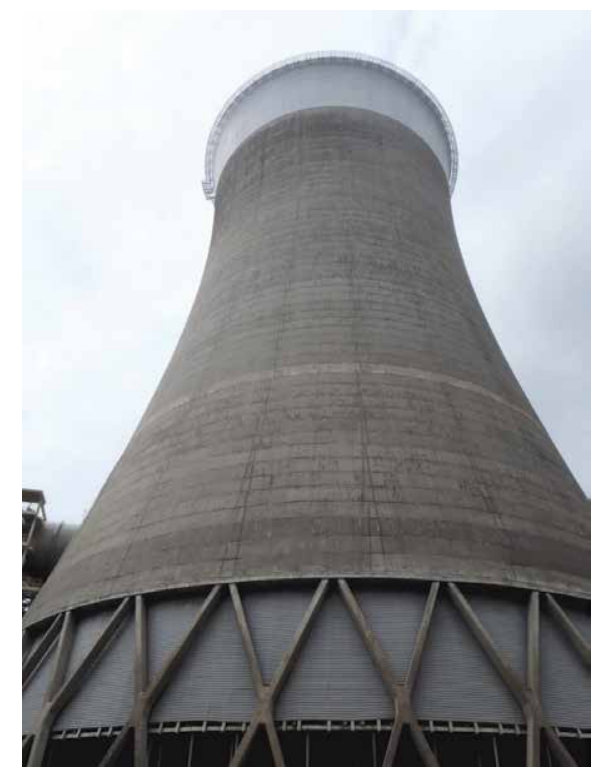

Figure 5. Cooling tower at Cardinal plant in eastern Ohio

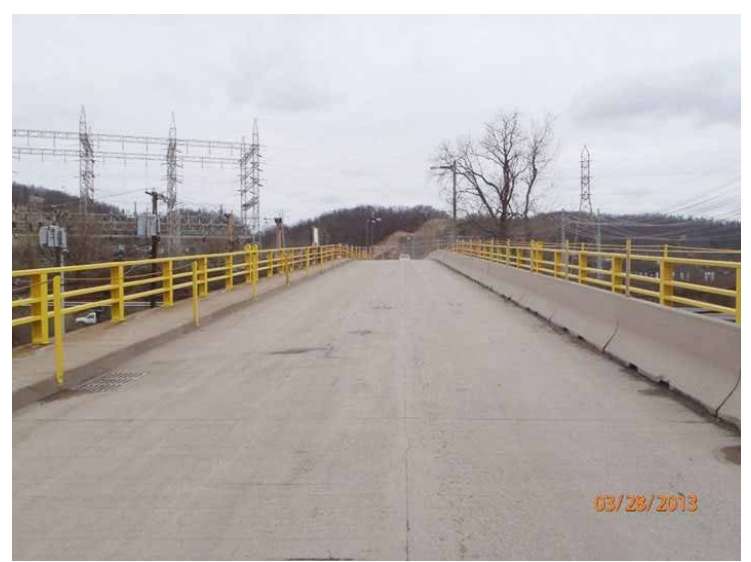

Figure 6. Access road bridge deck at Cardinal plant

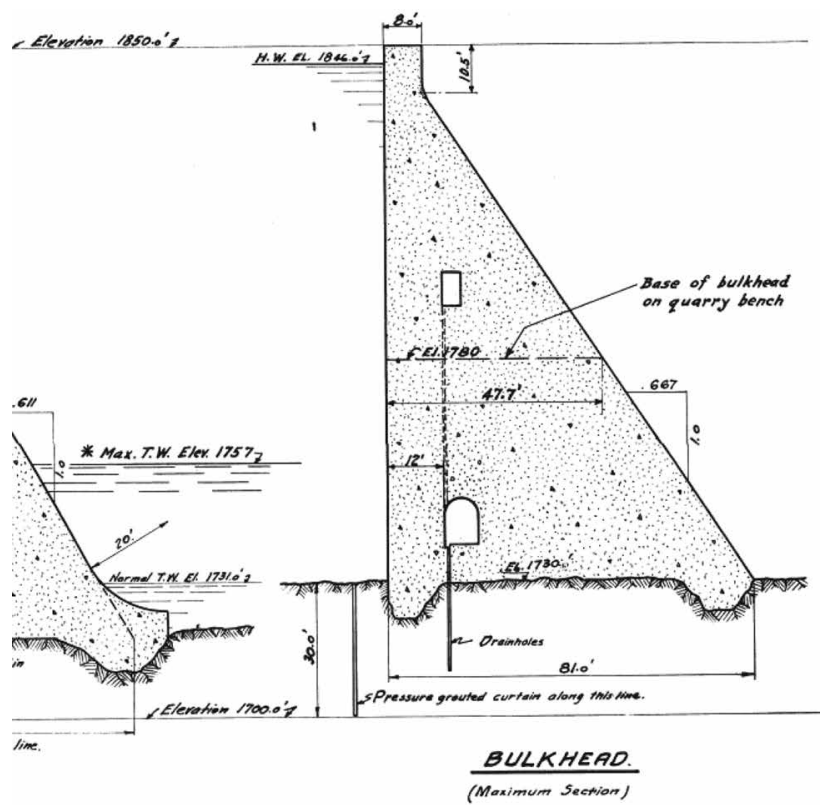

Figure 7. Claytor Hydroelectric dam cross section (from civil drawing provided by AEP) 


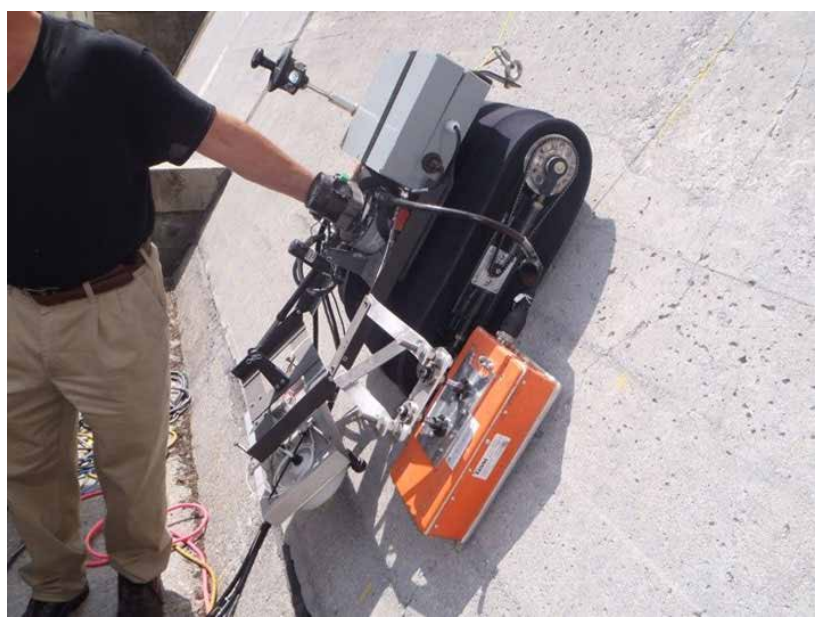

Figure 8. Experimental robot crawler used for NDE of Claytor dam

image is shown next to the thermal image for comparison. These structures are part of current research being performed by the authors of this review article.

This paper presents a review of the limited research performed in infrared thermography for detecting defects in concrete structures. In the next section first IRT for concrete defect detection in a laboratory setting is reviewed where the majority of the research is performed. Next, research on IRT in real concrete structures is summarized.

\section{IRT for concrete defect detection in a laboratory setting}

Yehia et al. (2007) compare various NDE methods for detecting defects in concrete bridge decks using a laboratory-created bridge slab. The authors apply IRT and other NDE methods, such as ground penetrating radar (GPR), to lab samples of representative bridge deck slabs. For the IRT testing, the specimens were subjected to solar heating as would be the case in a real world test. The authors conclude that IRT is the fastest method for detecting defects in concrete structures such as bridge slabs compared to

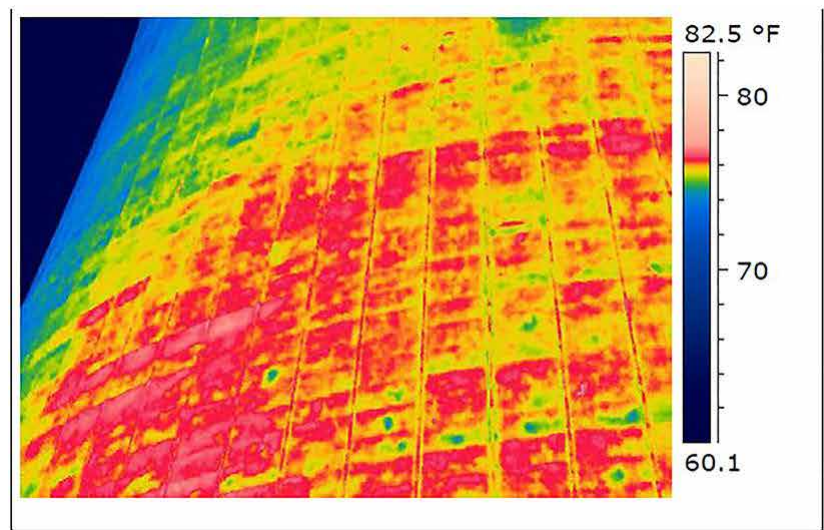

a)

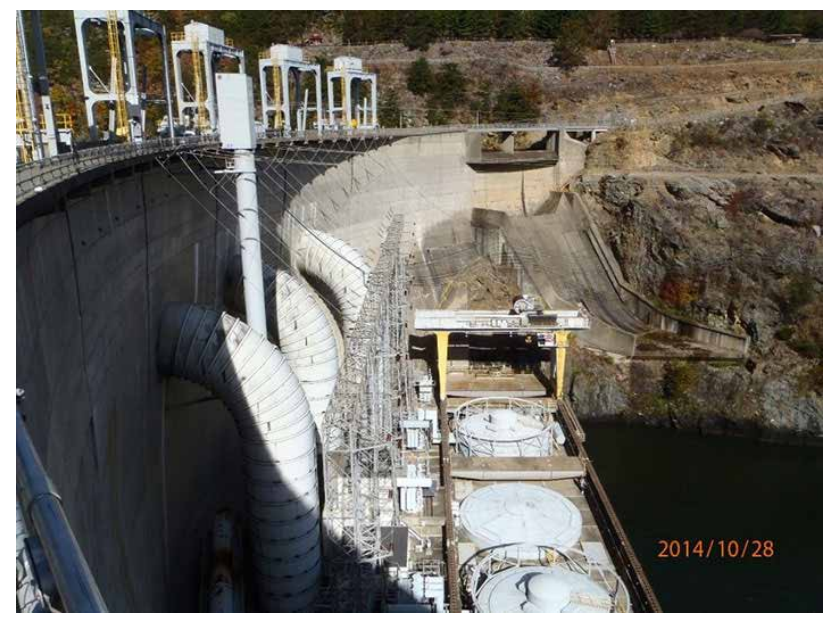

Figure 9. Smith Mountain Hydroelectric facility and dam

GPR. Determining the depth of the defect depends on environmental conditions such as the amount of solar heating and the time it takes for the structure to heat or cool.

Maierhofer et al. (2007) evaluate the effects of air-entrainment and porous aggregates in concrete mix designs (Rafiei et al. 2017) and how they affect thermal images for damage detection of reinforced concrete specimens in the form of slab structures. The authors conclude that the more porous mixes offer greater thermal conductivity and thus provide a better chance that defects in the concrete will be detected.

Cheng et al. (2008) apply IRT to detect concrete defects in mock ups of concrete walls and slabs. Other NDE methods were performed on the specimens as well including elastic wave methods, impact echo, and coin tapping. For the IRT test, the specimens were heated using halogen lamps to simulate solar heating. The authors report that smaller defect depths were detected sooner than deeper defects using IRT. The other NDE methods were found to be time consuming but complementary to IRT to confirm IRT defect detection.

Aggelis et al. (2010) use IRT to detect damage in concrete slab-like samples heated in an oven and further evaluate the extent of the damage with ultrasonic scanning. The

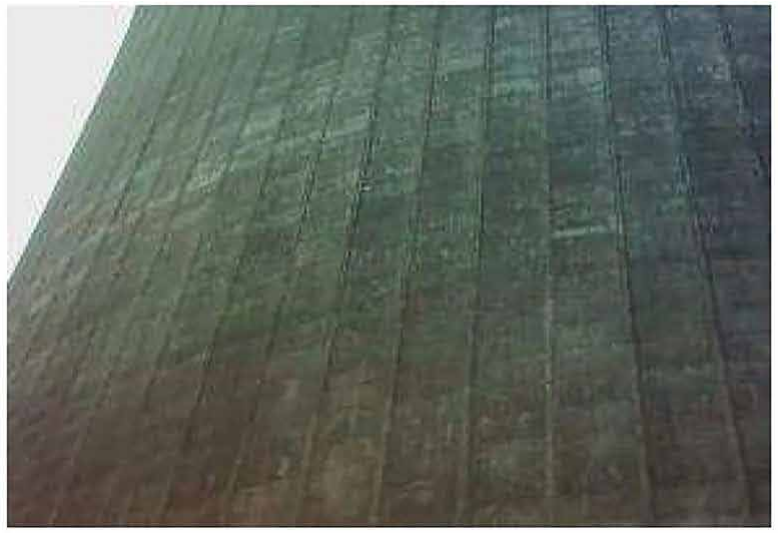

b)

Figure 10. a) Thermal image of a cooling tower at Amos plant located in central West Virginia; b) The visual image 
authors determined that IRT is a good technique for quickly quantifying the extent of the defects in the concrete while the ultrasonic scanning provided greater details of the defects. Aggelis et al. (2011) continue the research with a greater focus on the ultrasonic scanning component of the concrete damage detection and characterization of the damage.

Al-Hadhrami et al. (2012) investigate the use of IRT to detect damage in slab-like concrete samples prepared in the laboratory with a focus on how IRT varies with different concrete mix designs. The authors propose that IRT can be used to evaluate concrete density but also note that further studies are needed to validate the work.

Kee et al. (2012) apply IRT to a full-scale simulated reinforced concrete bridge deck and compare it to aircoupled impact-echo (ACIE) testing to detect defects in the concrete. ACIE is an automated or semi-automated technique that simulates manual impact hammer or chain dragging testing of concrete for delamination. The authors determine that overnight cooling of the specimen provided the best results for IRT to detect both shallow and deep defects. ACIE was able to detect shallow defects but was not as effective as IRT to detect deeper defects.

Farrag et al. (2016) investigate the use of IRT on concrete bridge decks by applying the technique to a slab created in the laboratory. The authors propose using the method as a health monitoring technique (Qarib, Adeli 2014; Amezquita-Sanchez, Adeli 2016) to compare a healthy deck to a potentially defective deck and not as a stand-alone method for damage or defect detection.

Zhao and Chen (2013) use IRT for detecting defects in a model of a concrete retaining wall. The laboratory setting provides a controlled environment that helps to limit the possibility of external factors that could inhibit the proper capture of thermal images. This type of research, however, does not provide solutions to the potential issues that arise from real world applications of IRT on large structures.

\section{Research on IRT in real concrete structures}

Most of the reported real concrete structure applications of IRT are about evaluating the condition of concrete bridge decks to detect delamination and cracks or other defects in the concrete. Maser and Roddis (1990) appears to be the first published work to use IRT for condition assessment of concrete structures with the method used on bridge decks. The authors report that IRT was able to predict defects within $5 \%$ of the measured defects in the bridge decks evaluated using traditional concrete condition assessment methods.

Pla-Rucki and Eberhard (1995) evaluate different imaging techniques for assessment of concrete bridge decks including radiography, microwave B-scan, and IRT. The authors report that IRT provides large scale condition assessment better than the other methods but is not able to provide much detail on the nature of the defects. As such, other traditional NDE techniques such as radiography or field-applied acoustical techniques such as hammer test- ing or chain dragging are needed to provide confirmation and/or nature of the defects.

Naik et al. (1997) apply IRT for evaluating concrete bridge decks to map cracking and other defects such as delamination of old patchwork. The investigation was carried out on an in-service freeway bridge in Milwaukee, Wisconsin. The authors report that IRT is effective in detecting defects on a large scale by correctly identifying delamination in the bridge deck. The areas identified by IRT were confirmed with hammer sounding the concrete.

Vaghefi et al. (2011) utilize IRT to detect subsurface cracks and delamination in concrete bridge decks and beams prepared in the laboratory as a precursor to work performed by Vaghefi et al. (2015) to apply the same method explicitly on in-service bridge decks. The authors used commercially available software to compile the IRT data to aid in mapping the defects. Additional post processing was performed to quantify the number of pixels in the IRT image that were within the temperature range of the identified defects. The authors were able to determine that approximately $0.21 \%$ of the bridge deck had defects in the form of spalls and delamination in the concrete. Some of the defects were confirmed with chain dragging. On the other hand, a significant number of the delamination was not detected by chain dragging. The authors performed core samples to verify whether a delamination exists or not in the discrepancy areas and found four of the seven core samples showed delamination while the other three appeared to be patched areas and not necessarily defects. Regardless, IRT proved to be a faster and ultimately more accurate method for bridge deck defect detection over the traditional chain drag method.

Oh et al. (2013) apply IRT and ACIE to an actual inservice bridge in Gainesville, Virginia and compare the results to the traditional chain drag method. Core samples were also performed to confirm the results. The authors report generally consistent results using different methods with IRT providing the fastest results.

Matsumoto (2014) uses IRT, image processing, and proprietary software to detect defects in concrete bridge decks in Orlando, Harris et al. (2016) use IRT on several in-service concrete bridge decks in Michigan, along with other remote sensing methods such as close-range photogrammetry, surface imagery, the commercially available GigaPan system, light detection and ranging or LiDAR (Park et al. 2007; Holgado-Barco et al. 2015; Riveiro et al. 2016), and radio detection and ranging (RADAR).

The application of IRT as a tool for damage detection is not limited to traditional concrete structures. Sirieix et al. (2007) examine a precast concrete culvert for defect identification using different NDE techniques, one of which is IRT. The other methods evaluated include electrical resistivity and capacity methods. The authors conclude that IRT is best suited for preliminary investigation to identify general areas of defects to be followed by other more labor-intensive methods for verifying the locations of the defects and determining the extent of the defects. Hing 
and Halabe (2010) use IRT to detect defects in glass fiberreinforced polymer bridge decks and compare it to GPR. Acknowledging the advantages and disadvantages of each method, the authors propose combining GPR with IRT to obtain a more detailed assessment by taking advantage of the deep-sensing capabilities of GPR with the sensitivity of IRT to find surface defects.

An important aspect of IRT is to understand the effects of solar heating, also referred to as solar loading, when obtaining thermal images of concrete structures. Washer et al. (2010) consider the different ways solar heating is influenced by environmental factors such as ambient temperature variations and wind. The authors consider only concrete bridge decks in their research. Lehmann et al. (2013) examine the effects of multiple climatic factors that affect the IRT image when applied to building structures and evaluate the thermal properties of the building's insulation and construction materials.

\section{Tools for post processing thermal images obtained from IRT}

Some work has been published on development of tools for post processing thermal images obtained from IRT. Maldague (2001) describes two methods for enhancing IRT images, one based on the spatial domain by manipulating the image pixels, and the other that works in the frequency domain and examines the rate of change in pixel intensities and filters out the high or low frequencies. Automated image analysis techniques include using advanced neural network techniques to identify defects automatically (Adeli, Hung 1995; Adeli, Park 1998; Siddique, Adeli 2013; Dai et al. 2015). Such techniques require prior knowledge of the defect in the form of a database of prior defects to train the model. Applying these techniques to large concrete structures where defects may vary considerably throughout the structure is challenging and requires further research. As such, NDE methods such as the ultrasonic pulse echo technique or ground penetrating radar are often needed to verify whether defects exist or not. Zhao and Chen (2013) use standard MATLAB tools to help enhance the thermal images of concrete retaining walls and to calculate the quantities of the defective areas.

Teza (2014) presents a MATLAB Toolbox, THIMRAN, to analyze IRT images to detect damage in large structures by evaluating time-lapsed images and comparing temperature changes from image to image. That tool is implemented for a building structure made of brick masonry and on a rock face subject to landslides.

\section{Final comments}

Health monitoring and damage detection of large structures such as bridges and high-rise buildings has been a very active area of research in recent years (Cha, Buyukozturk 2015; Karami, Akbarabadi 2016; Lei et al. 2016; Shan et al. 2016). The two main approaches explored by researchers are vibration-based health monitoring (Zhong,

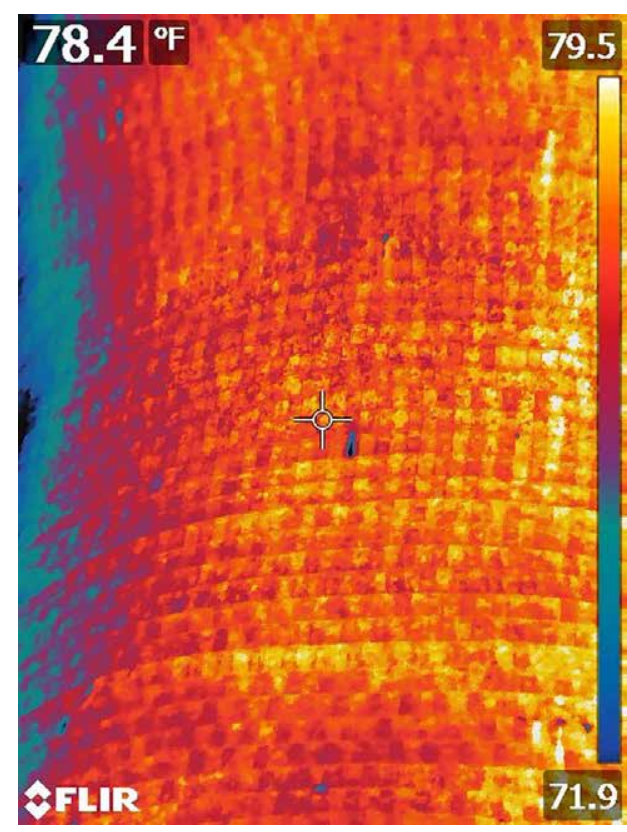

Figure 11. Thermal image of the north face of a cooling tower at Mitchell plant located in north-central West Virginia

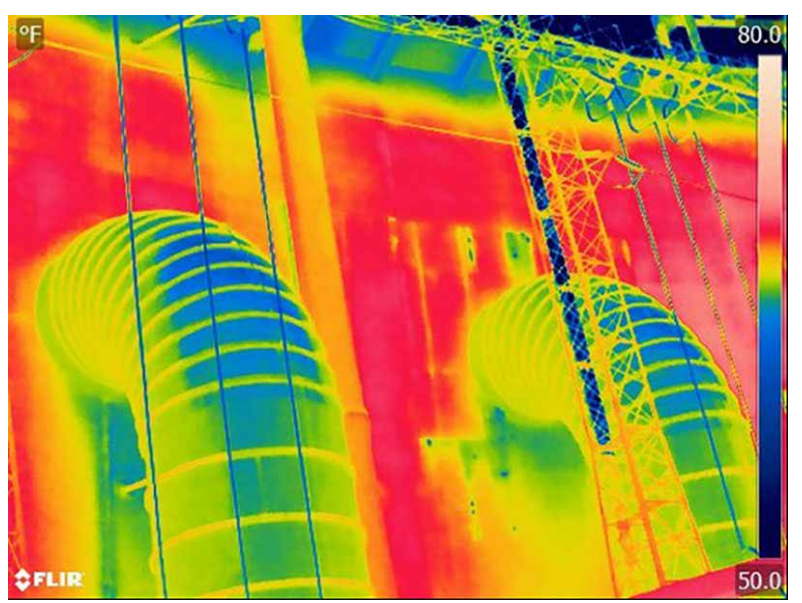

Figure 12. Thermal image of Smith Mountain Dam

Xiang 2016; Yuen, Mu 2015; Perez-Ramirez et al. 2016) and camera-based vision technology (Yeum, Dyke 2015). Another approach is application of terrestrial laser scanning (Park et al. 2007, 2015). IRT remains to be another promising technology for economical health monitoring of structures. However, challenges remain for applying the IRT to large scale three-dimensional concrete structures such as power plant cooling towers and hydroelectric dams because of the unique environmental considerations and the large amount of data that need to be interpreted. Renshaw et al. (2014) perform IRT on lab samples of concrete slabs and on a concrete dam structure. The authors conclude that IRT is capable of detecting cracks, voids, delamination, and other anomalies over wide areas of the dam very quickly compared to traditional methods. To the best of the authors' knowledge there are no published works demonstrating the implementation of IRT on 
cooling towers. However, IRT is currently being explored by American Electric Power (AEP) as an experimental tool for detecting defects. Figure 11 presents a thermal image from one of the cooling towers that is the subject of on-going research by the authors and AEP. New post processing techniques are currently being developed to detect defects. The research is also being extended to two of AEP's hydroelectric facilities: Claytor and Smith Mountain, as mentioned previously in this article. A sample thermal image from Smith Mountain dam is presented in Figure 12.

\section{Conclusions}

The authors hope this review article creates further interest to apply the IRT technology for health monitoring of large concrete structures. The success of IRT to detect defects or damage in large concrete structures would be a major breakthrough in NDE inspections of large structures such as dams and cooling towers as traditional methods are very costly and time consuming.

\section{References}

Adeli, H.; Hung, S. L. 1995. Machine learning - Neural networks, genetic algorithms, and fuzzy systems. New York: John Wiley and Sons.

Adeli, H.; Park, H. S. 1998. Neurocomputing for design automation. Boca Raton, Florida: CRC Press.

https://doi.org/10.1201/9781315214764

Aggelis, D. G.; Kordatos, E. Z.; Soulioti, D. V.; Matikas, T. E. 2010. Combined use of thermography and ultrasound for the characterization of subsurface cracks in concrete, Construction and Building Materials 24(10): 1888-1897. https://doi.org/10.1016/j.conbuildmat.2010.04.014

Aggelis, D. G.; Kordatos, E. Z.; Strantza, M.; Soulioti, D. V.; Matikas, T. E. 2011. NDT approach for characterization of subsurface cracks in concrete, Construction and Building Materials 25(7): 3089-3097.

https://doi.org/10.1016/j.conbuildmat.2010.12.045

Al-Hadhrami, L. M.; Maslehuddin, M.; Shameem, M.; Ali, M. R. 2012. Assessing concrete density using infrared thermographic (IRT) images, Infrared Physics \& Technology 55(5): 442-448. https://doi.org/10.1016/j.infrared.2012.04.004

Amezquita-Sanchez, J. P.; Adeli, H. 2016. Signal processing techniques for vibration-based health monitoring of structures, Archives of Computational Methods in Engineering 23(1): 1-15. https://doi.org/10.1007/s11831-014-9135-7

Cha, Y. J.; Buyukozturk, O. 2015. Structural damage detection using modal strain energy and hybrid multi-objective optimization, Computer-Aided Civil and Infrastructure Engineering 30(5): 347-358. https://doi.org/10.1111/mice.12122

Cheng, C.-C.; Cheng, T.-M.; Chiang, C.-H. 2008. Defect detection of concrete structures using both infrared thermography and elastic waves, Automation in Construction 8(1): 87-92. https://doi.org/10.1016/j.autcon.2008.05.004

Dai, H.; Wang, W.; Zhang, H. 2015. A multiwavelet neural network-based response surface method for structural reliability analysis, Computer-Aided Civil and Infrastructure Engineering 30(2): 151-162. https://doi.org/10.1111/mice.12086

Farrag, S.; Yehia, S.; Qaddoumi, N. 2016. Investigation of mixvariation effect on defect-detection ability using infrared thermography as a nondestructive evaluation technique, Journal of Bridge Engineering 21(3).

https://doi.org/10.1061/(ASCE)BE.1943-5592.0000779

Guimaraes, M. 2014. Enhanced inspection of hydroelectric concrete structures. Report 3002004459. Electric Power Research Institute, Palo Alto, CA.

Harris, D.; Brooks, C.; Ahlborn, T. 2016. Synthesis of field performance of remote sensing strategies for condition assessment of in-service bridges in Michigan, Journal of Performance of Constructed Facilities 30(5).

https://doi.org/10.1061/(ASCE)CF.1943-5509.0000844

Hing, C.; Halabe, U. 2010. Nondestructive testing of GFRP bridge decks using ground penetrating radar and infrared thermography, Journal of Bridge Engineering 15(4): 391-398. https://doi.org/10.1061/(ASCE)BE.1943-5592.0000066

Holgado-Barco, A.; González-Aguilera, D.; Arias-Sanchez, P.; Martinez-Sanchez, J. 2015. Semi-automatic extraction of road horizontal alignment from a mobile LiDAR system, Computer-Aided Civil and Infrastructure Engineering 30(3): 217-228. https://doi.org/10.1111/mice.12087

Karami, K.; Akbarabadi, S. 2016. Developing a smart structure using integrated subspace-based damage detection and semiactive control, Computer-Aided Civil and Infrastructure Engineering 31(11): 887-903. https://doi.org/10.1111/mice.12231

Kee, S.; Oh, T.; Popovics, J.; Arndt, R.; Zhu, J. 2012. Nondestructive bridge deck testing with air-coupled impact-echo and infrared thermography, Journal of Bridge Engineering 17(6): 928-939.

https://doi.org/10.1061/(ASCE)BE.1943-5592.0000350

Lehmann, B.; Ghazi, W. K.; Frank, T.; Vera, B. C.; Tanner, C. 2013. Effects of individual climatic parameters on the infrared thermography of buildings, Applied Energy 110(10): 29-43. https://doi.org/10.1016/j.apenergy.2013.03.066

Lei, Y.; Zhou, H.; Lai, Z. L. 2016. A computationally compact algorithm for real-time detection of abrupt structural stiffness degradations, Computer-Aided Civil and Infrastructure Engineering 31(6): 465-480. https://doi.org/10.1111/mice.12217

Maierhofer, C.; Arndt, R.; Rollig, M. 2007. Influence of concrete properties on the detection of voids with impulse-thermography, Infrared Physics \& Technology 49(3): 213-217. https://doi.org/10.1016/j.infrared.2006.06.007

Maldague, X. 2001. Theory and practice of infrared technology for nondestructive testing. New York: John Wiley \& Sons.

Maser, K.; Roddis, W. 1990. Principles of thermography and radar for bridge deck assessment, Journal of Transportation Engineering 116(5): 583-601.

https://doi.org/10.1061/(ASCE)0733-947X(1990)116:5(583)

Matsumoto, M. 2014. Non-destructive bridge deck assessment using image processing and infrared thermography, in Transportation Research Board 93 ${ }^{\text {rd }}$ Annual Meeting, 2014. Washington: Transportation Research Board.

Naik, T.; Singh, S.; Zachar, J. 1997. Application of infrared thermography technique for evaluation of existing concrete structures, in Seventh International Conference and Exhibition "Structural Faults \& Repair - 97", July 1997, Edinburgh, Scotland.

Oh, T.; Kee, S.; Arndt, R.; Popovics, J.; Zhu, J. 2013. Comparison of NDT methods for assessment of a concrete bridge deck, Journal of Engineering Mechanics 193(3): 305-314. https://doi.org/10.1061/(ASCE)EM.1943-7889.0000441

Park, H. S.; Lee, H. M.; Adeli, H.; Lee, I. 2007. A new approach for health monitoring of structures: Terrestrial laser scanning, Computer-Aided Civil and Infrastructure Engineering 22(1): 19-30. 
Park, S. W.; Park, H. S.; Kim, J. H.; Adeli, H. 2015. 3D displacement measurement model for health monitoring of structures using a motion capture system, Measurement 59: 352-362. https://doi.org/10.1111/j.1467-8667.2006.00466.x

Perez-Ramirez, C. A.; Amezquita-Sanchez, J. P.; Adeli, H.; Valtierra-Rodriguez, M.; Camarena-Martinez, D.; Rene RomeroTroncoso, R. J. 2016. New methodology for modal parameters identification of smart civil structures using ambient vibrations and synchrosqueezed wavelet, Engineering Applications of Artificial Intelligence 48: 1-16.

https://doi.org/10.1016/j.engappai.2015.10.005

Pla-Rucki, G.; Eberhard, M. 1995. Imaging of reinforced concrete: State-of-the-art review, Journal of Infrastructure Systems 1(2): 134-141.

https://doi.org/10.1061/(ASCE)1076-0342(1995)1:2(134)

Qarib, H; Adeli, H. 2014. Recent advances in health monitoring of civil structures, Scientia Iranica - Transaction A: Civil Engineering 21(6): 1733-1742.

Rafiei, M. H.; Khushefati, W. H.; Demirboga, R.; Adeli, H. 2017. Novel approach for concrete mix design using neural dynamics model and the virtual lab concept, ACI Materials Journal 14(1): 117-127.

Riveiro, B.; Lourenço, P. B.; Oliveira, D. V.; González-Jorge, H.; Arias, P. 2016. Automatic morphologic analysis of quasi-periodic masonry walls from LiDAR, Computer-Aided Civil and Infrastructure Engineering 31(4): 305-319.

https://doi.org/10.1111/mice.12145

Siddique, N.; Adeli, H. 2013. Computational intelligence Synergies of fuzzy logic, neural networks and evolutionary computing. West Sussex: Wiley.

https://doi.org/10.1002/9781118534823

Sirieix, C.; Lataste, J. F.; Breysse, D.; Naar, S.; and Derobert, X. 2007. Comparison of nondestructive testing: Infrared thermography, electrical resisitivity and capacity methods for assessing a reinforced concrete structure, Journal of Building Appraisal 3(1): 77-88.

https://doi.org/10.1057/palgrave.jba.2950065

Renshaw, J.; Guimaraes, M.; Scott, D. 2014. Thermographic inspection of massive structures, AIP Conference Proceedings 1581: 978-984. https://doi.org/10.1063/1.4864927

Shan, J.; Shi, W.; Lu, X. 2016. Model reference health monitoring of hysteretic building structure using acceleration measurement with test validation, Computer-Aided Civil and Infrastructure Engineering 31(6): 449-464.

https://doi.org/10.1111/mice.12172

Teza, G. 2014. THIMRAN: MATLAB Toolbox for thermal image processing aimed at damage recognition in large bodies, Journal of Computing in Civil Engineering 28(4). https://doi.org/10.1061/(ASCE)CP.1943-5487.0000368

Vaghefi, K.; de Melo e Silfa, H.; Harris, D.; Ahlborn, T. 2011. Application of thermal IR imagery for concrete bridge inspection, in Proceedings of the PCI National Bridge Conference, 2011, Salt Lake City, UT.

Vaghefi, K.; Ahlborn, T.; Harris, D.; Brooks, C. 2015. Combined imaging technologies for concrete bridge deck condition assessment, Journal of Performance of Construction Facilities 29(4). https://doi.org/10.1061/(ASCE)CF.1943-5509.0000465

Yehia, S.; Abudayyeh, O.; Nabulsi, S.; Abdelqader, I. 2007. Detection of common defects in concrete bridge decks using nondestructive evaluation techniques, Journal of Bridge Engineering 12(2): 215-225.

https://doi.org/10.1061/(ASCE)1084-0702(2007)12:2(215)
Washer, G.; Fenwick, R.; Bolleni, N. 2010. Effects of solar loading on infrared imaging of subsurface features in concrete, Journal of Bridge Engineering 15(4): 384-390. https://doi.org/10.1061/(ASCE)BE.1943-5592.0000117

Yeum, C. M.; Dyke, S. J. 2015, Vision based automated crack detection for bridge inspection, Computer-Aided Civil and Infrastructure Engineering 30(10): 759-770. https://doi.org/10.1111/mice.12141

Yuen, K. V.; Mu, H. Q. 2015. Real-time system identification: An algorithm for simultaneous model class selection and parametric identification, Computer-Aided Civil and Infrastructure Engineering 30(10): 785-801. https://doi.org/10.1111/mice.12146

Zhao, G.; Chen, J. G. 2013. Infrared thermo-graphic inspection technique for concrete retaining wall, Electronic Journal of Geotechnical Engineering 18(1): 1521-1528.

Zhong, Y.; Xiang, J. 2016, A two-dimensional plum-blossom sensor array-based multiple signal classification method for impact localization in composite structures, Computer-Aided Civil and Infrastructure Engineering 31(8): 633-643. https://doi.org/10.1111/mice.12198 